\title{
FSK-Based Energy and Signal Composite Modulation Strategy for Switched Reluctance Drive System
}

\author{
Fei Li ${ }^{1}$, Chao Wang ${ }^{2} \mathbb{1}$, Kecheng $\mathrm{Li}^{2}$, Xin Wang ${ }^{2}$, Dongsheng $\mathrm{Yu}^{2, *} \mathbb{1}$ and Herbert H. C. Iu ${ }^{3, *}$ \\ 1 School of Electrical Engineering and Automation, Jiangsu Normal University, Xuzhou 221116, China; \\ lifei_jsnu@jsnu.edu.cn \\ 2 School of Electrical and Power Engineering, China University of Mining and Technology, Xuzhou 221116, \\ China; TS17130024A3@cumt.edu.cn (C.W.); TS18130046A31@cumt.edu.cn (K.L.); \\ TS17130220p3@cumt.edu.cn (X.W.) \\ 3 School of Electrical, Electronic and Computer Engineering, The University of Western Australia, 35 Stirling \\ Highway, Crawley, WA 6009, Australia \\ * Correspondence: dawson@cumt.edu.cn (D.Y.); herbert.iu@uwa.edu.au (H.H.C.I.)
}

Received: 19 May 2020; Accepted: 27 June 2020; Published: 2 July 2020

\begin{abstract}
A DC-distributed power system consists of a large quantity of subsystems with power converters. The interaction among these subsystems will affect the operation performance of the whole system. Therefore, data communication plays a very important role in system control and equipment monitoring. The present study proposes a dual modulation method of power/signal based on Switched Reluctance Drive (SRD), which can transmit signals simultaneously with power conversion and can promise data communication of the system with lower cost. This proposed method uses the ripple inherent as the carrier of the signal in the power circuit and adopts Pulse width modulation (PWM)/frequency shift keying (FSK) composite modulation to realize the reverse transmission of signals from the load to the power supply. Results of simulations and experiments indicate that this new method is effective in data communication.
\end{abstract}

Keywords: DC-distributed power system; switched reluctance motor; data communication; power/signal dual modulation

\section{Introduction}

Energy is considered as necessary support in modern technological and industrial progress [1,2]. Among multiple attempts that aim at optimizing the energy efficiency and developing new energy, much attention of researchers has been given to distributed power generation technology and its application in a micro-grid.

Distributed power generation [3] is a small-scale power generation built near power users and relies on scattered energy for power generation, with its output ranging from several kilowatts to hundreds of megawatts. The distributed power system consists of two parts: distributed generation power supply and distributed power supply. The former focuses on the production of electrical energy, while the latter emphasizes the transmission of electrical energy. Compared with the Centralized Power System (CPS), the distributed power system is a modular high-power supply system that connects several small and medium-sized power supply modules in parallel $[4,5]$ and is widely used in aerospace power supply, power system, new energy vehicles, etc. Meanwhile, as an important component of smart grid, a distributed power system contains a variety of power electronic equipment [6]. With the development of smart grids, distributed power systems integrate communication technology, sensor measurement technology, and information technology to meet the needs of power generation, grid operation, and terminal power consumption [7]. The distributed power supply and communication 
technology are introduced into the smart grid to achieve the real-time information exchange and the supply balance at the device level and to establish a highly automated energy exchange network with bidirectional flow of power and information [8]. Figure 1 shows the structure of a distributed power system.

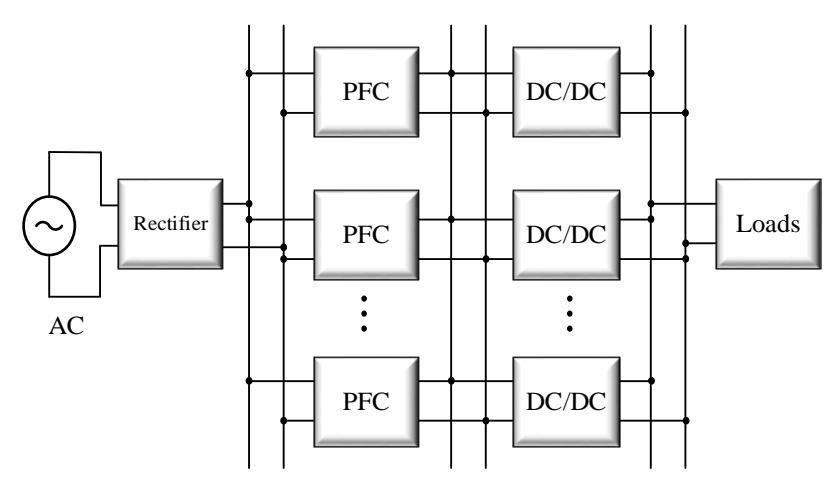

Figure 1. Schematic diagram of distributed power system.

In the traditional distributed power system, an additional communication circuit is introduced to the power circuit to receive control commands or exchange data between power converters. For example, Controller Area Network (CAN), Recommended Standard-485 (RS-485), and other wired communication technologies [9] are widely used in distributed power systems. However, the system becomes more complex and its installation cost increases with additional communication circuits. As in wireless transmissions such as WiMAX, Wi-Fi and Zigbee with no hardware lines, their independent signal transmission devices also need be optimized for their reliability and adaptability to environment.

In order to simplify the communication system of the power grid and to reduce the communication cost, recent research focuses on Power over Ethernet (PoE), a new communication technology that can combine two types of communication and power systems. The compound communication technology of energy signals has gone through three developmental stages as encapsulation, integration, and fusion. The schematic diagram is shown in Figure 2.
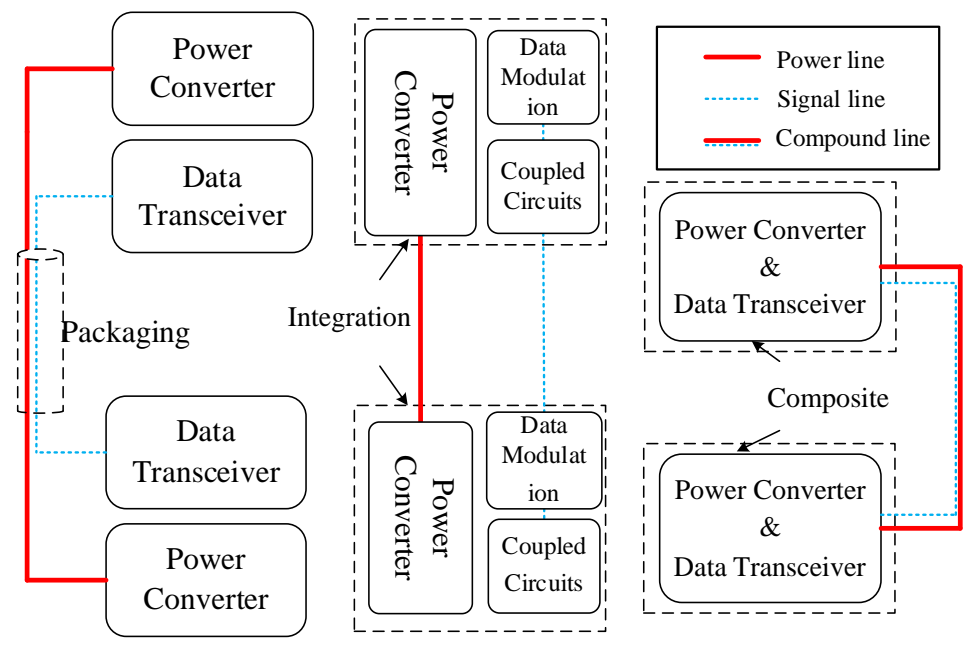

Figure 2. Schematic diagram of the development stage of compound communication technology.

At present, the compound communication technology is divided into three categories: (1) using the existing power line for signal modulation, such as power line communication (PLC); (2) using independent communication lines, such as the bus power supply method in the IEC61158-2 standard; and (3) adding power supply devices to existing communication lines. The power line communication technology has become a research focus since it was proposed in the 1920s, for it has the advantages 
of simple networking, wide distribution, no need for rewiring, and convenient operation [10,11]. The principle of PLC uses power lines of various voltage levels as media for voice or data transmission. It has been widely applied in various areas such as automatic electricity meter reading, power supply management, and grid load control $[12,13]$.

Recent decades have witnessed progresses in power line communication. In [14], the author proposed a new DC-bus PLC system powered by a synchronous switching converter. Implementation of the PLC technology is simple and only requires proper modulation of the controllable switching devices in the converter. The research in [15] studied the application of PLC technology in the distributed digitally controlled DC-DC converters. A small duty-cycle perturbation at half of switching frequency is introduced to enhance the signal of low power transmission. An enhanced PLC strategy using switching frequency modulation is proposed in [16] to optimize the power converter by improving the reliability of DC microgrids operation. The literature of [17] proposes a solution that only uses the signal during the switching phase. However, such a proposal still has many limitations due to the high frequency content of the signal and the possible attenuation on the power line. In [18], the frequency and duty-cycle modulation methods are mainly discussed. By modulating the duty-cycle of the PWM signal at the half of switching frequency, the researcher introduces perturbation to the common supply bus voltage, which increases the transmission within the bus bandwidth and ensures the distance and accuracy of the signal transmission. Researchers in [19] also proposed a compound modulation method for electrical energy signals, using the intrinsic ripple initiated in switch mode power supplies as signal carriers to implement a narrow-frequency PLC in a distributed DC source system. The above researches on energy and signal compound transmission are all conducted on DC/DC converter circuit.

Switched Reluctance Drive (SRD), with its simple structure, reliable operation, and low cost, is used as the core part of a new speed control system. It can perform DC speed regulation and AC speed regulation and has been used in fans, compressors, traction locomotives, electric vehicles, aircraft, and other occasions [20]. Recently, a new modulation and demodulation strategy to DC power-line data transmission for Switched Reluctance Generator (SRG) integrated microgrid is proposed, of which the turn-on and turn-off angle are adopted to regulate the voltage ripple for carrying data [21]. In [22], a soft-PWM method to power/signal synchronous transmission for SRG based DC microgrids is presented. The switches are modulated to produce voltage ripples with specific frequency for data transmission. However, these is no article to discuss the possibility of power and signal synchronous transmission in SRD system. In order to reduce the impact of signal modulation on the operation of SRD as well as to improve the communication rate and the efficiency, this paper proposes a frequency shift keying (FSK) modulation method in the Free-wheeling (FW) section for complex transmission of energy signals. The proposed method separates the upper and lower transistors of the SRD power converter in the excitation section for speed control. The soft chopping method is used, and the FSK modulation signal is adopted in the freewheeling section to drive the lower transistors. Therefore, the corresponding switching ripple is superimposed on the bus. At the receiving end of the bus, the Fourier iterative algorithm is used to simplify the calculation and to demodulate the signal more efficiently. Simulations are modeled to verify the effectiveness of the proposed method.

\section{Compound Modulation Strategy of FSK Energy Signal}

Pulse width modulation (PWM) theory has been widely used for controlling power electronic circuits. The typical PWM waveform is shown in Figure 3, where $T$ is the period, $d$ is the duty cycle, $\tau T$ is the turn-on delay, and $\omega=2 \pi / T$. 


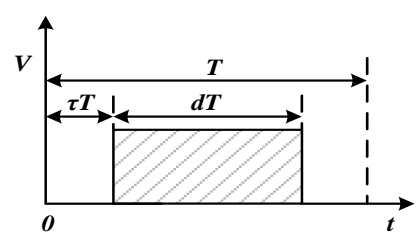

Figure 3. Typical pulse width modulation (PWM) waveform.

Fourier series expansion of PWM waveform can be obtained by

$$
\begin{gathered}
f(t)=a_{0}+\sum_{n=1}^{\infty} a_{n} \cos (n \omega t)+\sum_{n=1}^{\infty} b_{n} \sin (n \omega t) \\
a_{0}=d V \\
a_{n}=\frac{2 V}{n \pi} \sin (n d \pi) \cos (2 n \tau \pi+n d \pi) \\
b_{n}=-\frac{2 V}{n \pi} \sin (n d \pi) \sin (2 n \tau \pi+n d \pi) \\
c_{n}=\sqrt{a_{n}^{2}+b_{n}^{2}}=\frac{2 V}{n \pi}|\sin (n d \pi)|
\end{gathered}
$$

Assuming $a_{\mathrm{n}} \cos n \omega t+b_{\mathrm{n}} \sin n \omega t=c_{n} \cos \left(n \omega t+\varphi_{n}\right)$, Equation (1) can be simplified as

$$
\begin{aligned}
& f(t)=c_{0}+\sum_{n=1}^{\infty} c_{n} \cos \left(n \omega t+\varphi_{\mathrm{n}}\right) \\
& c_{n}=\frac{2 V}{n \pi}|\sin n d \pi|=2 V d \frac{|\sin n d \pi|}{n d \pi} \\
& \varphi_{n}=\arctan \left(-\frac{a_{n}}{b_{n}}\right)=n \pi(2 \tau+d)
\end{aligned}
$$

Note that $c_{0}$ is truly equal to $a_{0}$, by referring to (1) and (6).

As shown in Figure 4, the amplitude of the DC component is half of the corresponding value of the envelope $2 V d|S a(n d \pi)|$ at the zero point. The discrete amplitude terms of the fundamental wave and each harmonic are function values at each integer point when $n$ is increased from 1 to infinite. The spacing between two adjacent spectral lines is $1 / T$, indicating that each spectral line is located at an integer multiple of the fundamental frequency $f=1 / T$ and that the spectral line at $1 / d$ and its integer multiple are 0 .

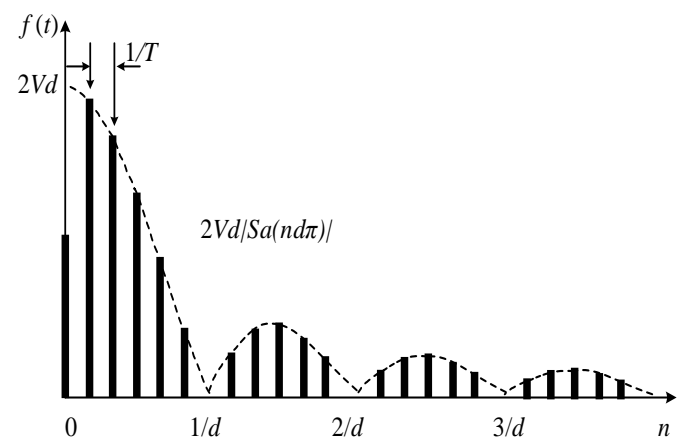

Figure 4. The coefficients of Fourier series expansion.

It can be seen from Equation (5) and Figure 4 that changing $f$ and $\varphi$ will not affect the DC component. Therefore, $f$ and $\varphi$ are relatively independent from $d$, indicating that the signal can be modulated by changing these two variables. Using the switching harmonic components generated at 
the input and output of the converter as the signal carrier, the frequency $f$ or phase $\varphi$ of the switching signal is adjusted by the data signal in correspondence with two basic methods of digital modulation of the switching ripple, i.e., the frequency shift keying (FSK) modulation and phase shift keying (PSK) modulation, respectively. FSK-based composite modulation means using the FSK method to modulate the transmitted signal as well as PWM to achieve power line communication.

This paper adopts the FSK modulation signal in the freewheeling section of the lower transistors of the SRD power circuit. When the signal is " 0 ", the switching frequency of the circuit is $f_{0}$; when the signal is " 1 ", the switching frequency is set to $f_{1}$. Meanwhile, the PWM method is adopted to control the upper transistors of SRD power circuit.

\section{Freewheeling Section Topology and Carrier Frequency Analysis}

The operation of SRD can be divided into two stages: excitation section and freewheeling section. Traditional control methods practically adjust the voltage on the windings during excitation. The freewheeling section is often ignored as it is uncontrollable. The freewheeling section refers to the interval between the off state to the next on state of the switching device. The magnetic energy on the winding during this section that has not been completely converted into mechanical energy is turned back to the power supply through the diode. The excitation freewheeling circuit of one-phase winding of power converter is shown in Figure 5.

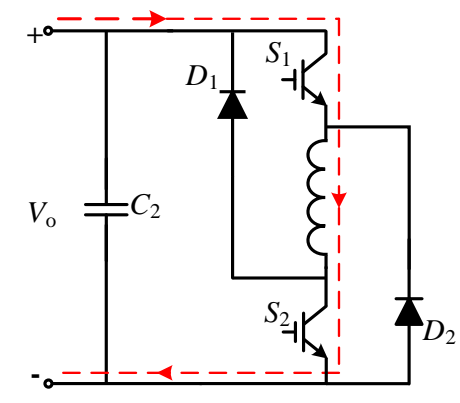

(a)

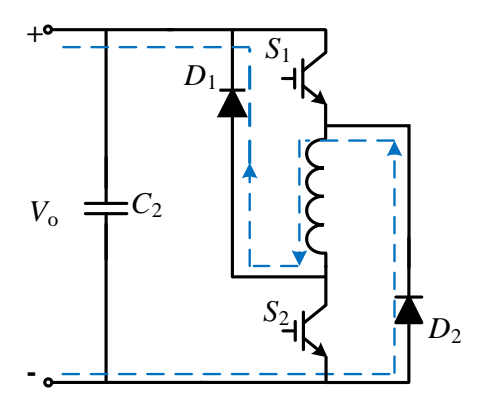

(b)

Figure 5. One phase working state of power converter: (a) excitation loop and (b) freewheeling loop.

The excitation circuit in Figure 5a is also called a positive voltage circuit, and the freewheeling circuit is called a negative voltage circuit. Moreover, a zero-voltage circuit also exists under certain switching conditions. The zero-voltage loop refers to a loop in which one device is turned on while the other device is turned off. The current does not have any interaction with the outside and only flows internally as shown in Figure 6. Compared with the negative voltage circuit, the winding of the zero-voltage circuit has no path to return energy to the power supply, thus avoiding frequent exchange of reactive power between the motor and the power supply. This feature has advantages such as being able to increase torque, to improve the utilization of the power converter capacity, to reduce the number of chopping, to suppress power supply voltage fluctuations, and to reduce torque ripple.
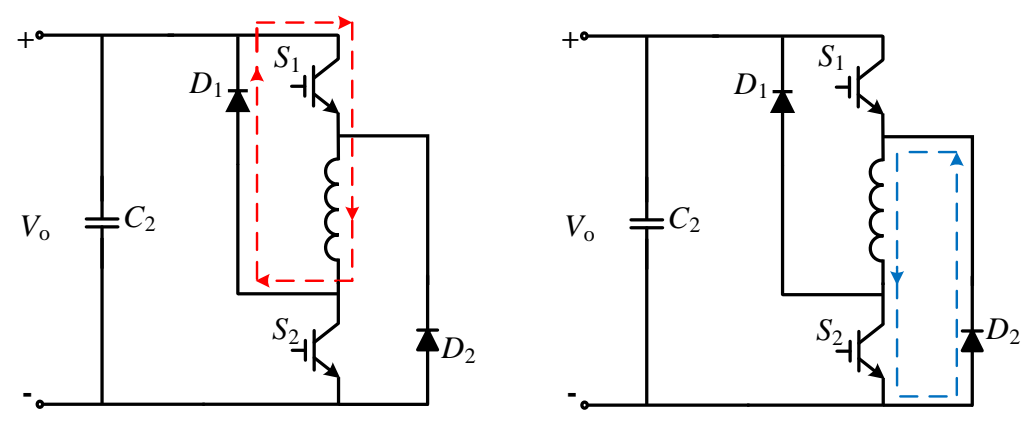

Figure 6. Zero-voltage loop. 
The chopper method corresponding to the negative voltage circuit is called hard chopper, and the chopper method corresponding to the zero-voltage circuit is called soft chopper [23]. Switching devices in excitation circuit is not allowed to be open normally, which will stop the winding from being excited. Similarly, the switching device is not allowed to be normally closed in the freewheeling circuit, which will block the path of the energy on the winding to the power supply. The control of the SRD is generally applied during the excitation circuit, while the switching device is completely turned off during the freewheeling circuit. If the signal modulation is introduced during the excitation circuit, the motor cannot be properly excited, which will weaken the performance of the motor. In order to secure the smooth operation of the motor, signal modulation can be performed in the freewheeling circuit. The present study, based on the above analysis, adopts a soft chopper to reduce switches and to suppress the power supply voltage fluctuation and torque ripple. Figure 7 shows the driving signals of the switching devices for each phase.

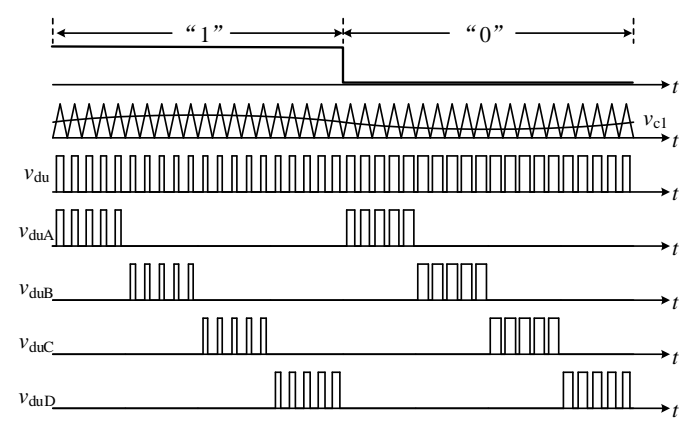

(a)

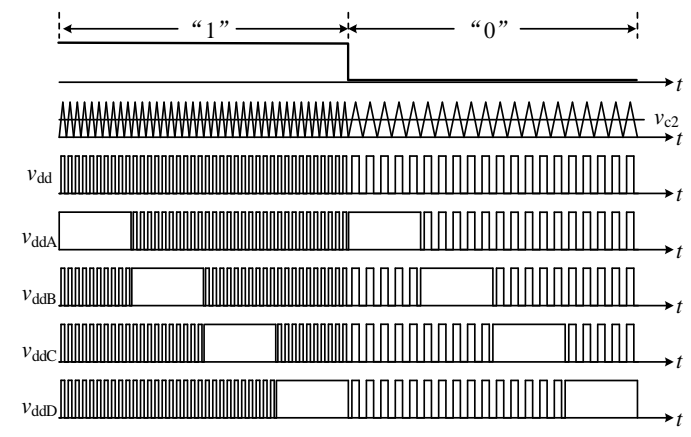

(b)

Figure 7. Driving signals waveforms of four-phase Switched Reluctance Drive (SRD): (a) driving signals of upper devices for 4 phases and (b) driving signals of lower devices for 4 phases.

It can be seen from the waveforms of the upper switching device driving signal in Figure 7a that the frequency and amplitude of the carrier wave remain constant and do not change with the transmitted signal. The amplitude of the modulation wave $v_{\mathrm{c} 1}$ changes according to the difference between the actual speed and the reference speed. The driving signal waveforms of the 2 Frequency Shift Keying (2FSK) modulation of the lower switching devices are shown in Figure $7 \mathrm{~b}$. When the regular triangle carrier wave transmits " 1 ", the frequency is $f_{1}$, and when it transmits " 0 ", the frequency is $f_{2}$. The amplitude and phase of the carrier remain unchanged. The PWM modulation wave $v_{\mathrm{c} 2}$ is a straight line, and its value is smaller than the maximum value of the carrier wave. $v_{\mathrm{c} 2}$ is taken as

$$
v_{\mathrm{c} 2}=\frac{1}{2} V_{\mathrm{M}}
$$

where $V_{\mathrm{M}}$ is the maximum value of the carrier wave. Comparing the carrier wave with the PWM wave, $v_{\mathrm{c} 2}$ achieves the driving signal as a pulse, with a fixed duty cycle of 0.5 . The lower switching devices of each phase remains normally closed during the excitation section, and the switching devices are controlled according to the driving signal $v_{\mathrm{dd}}$ in the freewheeling section, so that the bus voltage and current generate ripples with information. All signals such as the modulated $2 \mathrm{FSK}, v_{\mathrm{c} 2}$, and the signals from $v_{\mathrm{ddA}}$ to $v_{\mathrm{ddD}}$ are all related to the transmitted signal. Meanwhile, the upper switching devices remain normally open in the freewheeling section. Soft chopping is therefore achieved.

Due to the chopping in the freewheeling section, there will be changes in the phase current. The waveform of one phase current is shown in Figure 8. 


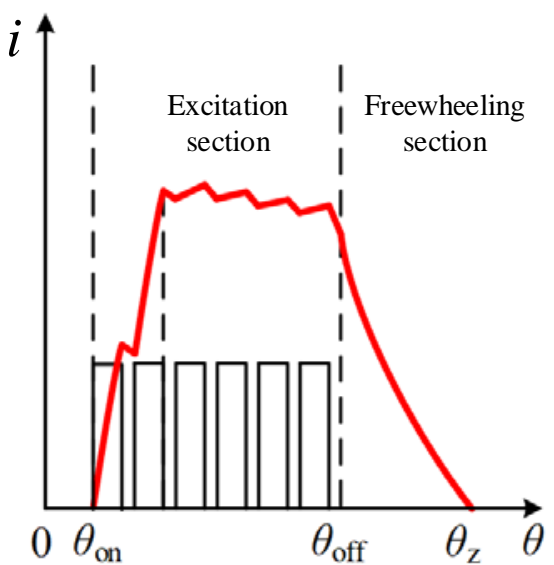

(a)

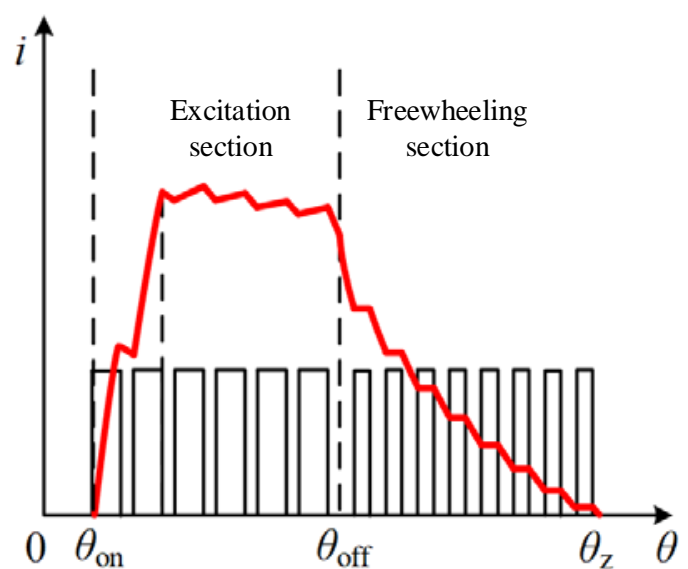

(b)

Figure 8. One phase waveform of chopper control: (a) current waveform of the excitation section and (b) current waveform of the freewheeling section.

Assuming that the motor speed is the same in both cases, it can be seen from Figure $8 \mathrm{a}, \mathrm{b}$ that the current is the same in the excitation section but different in the freewheel section. The uncontrolled phase current in the freewheel section is quickly and smoothly reduced to zero in Figure 8a, while the phase current with chopping in the freewheeling section gradually decreases in a step-like manner due to frequent switching between the negative-voltage loop and the zero-voltage loop. The time for the latter phase current to fall from the corresponding value at the turn-off angle to zero is about twice that for the former, and its current at each moment is also higher than that of the former. That means the phase current effective value of full chopper is larger, thus generating more electric torque.

In every $15^{\circ}$ interval, when one phase is in the excitation section, the other three phases are in the freewheeling section or the current has dropped to zero. As shown in Figure 9, there will be a minimum of a two-phase current superimposed at each moment. Since the upper and lower switching devices have two states, on and off, there are four combined states in the entire period. As any one of the four phases is excited, the other three phases are in the freewheeling section. Taking phases A and $\mathrm{B}$ as an example, when phase B is excited, phase A is in freewheeling section. There are four states combined in total, as shown in Figure 10, since carrier frequencies of the two phases, phase B with two states during excitation and phase A with two states during freewheeling, are different.

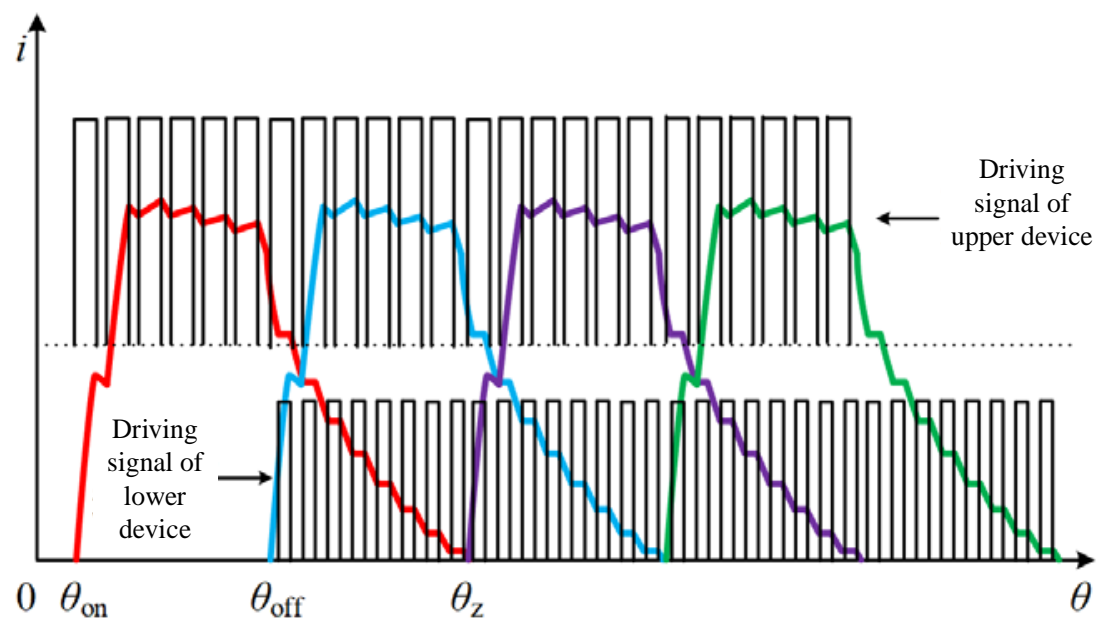

Figure 9. Four phases waveforms of full chopper. 


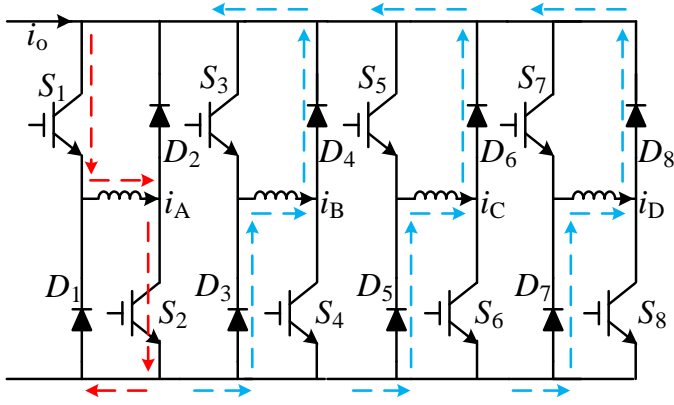

(a)

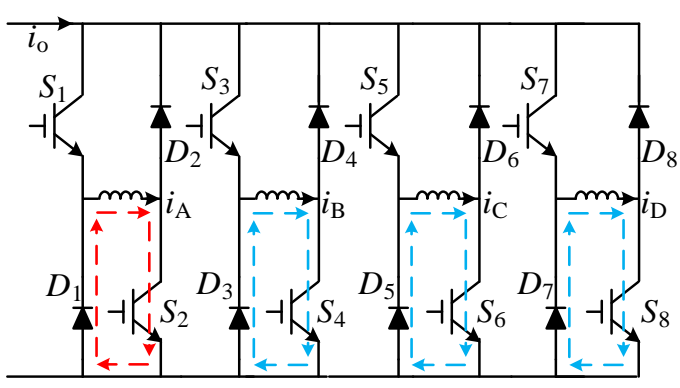

(c)

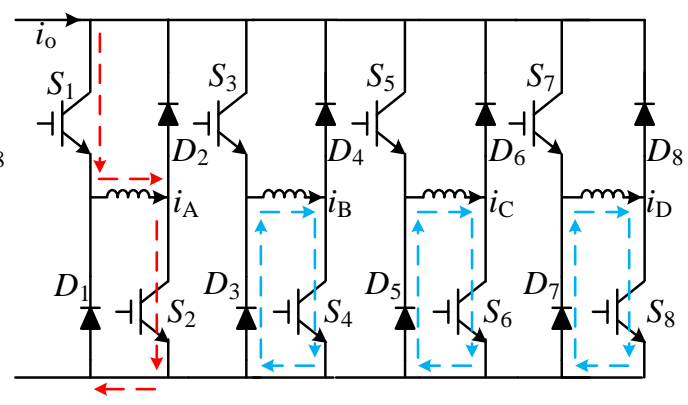

(b)

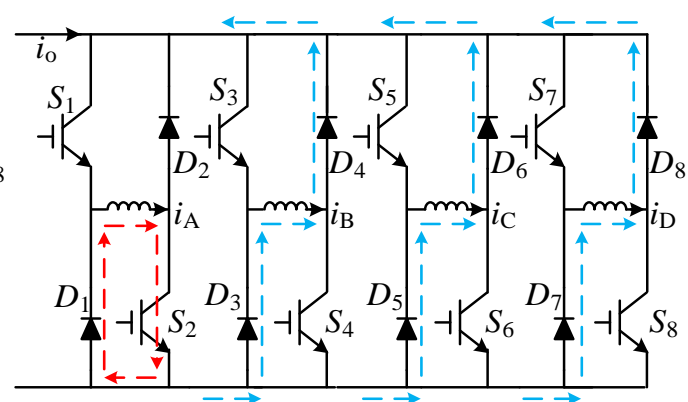

(d)

Figure 10. Four cases of speed regulating system: (a) case 1, (b) case 2, (c) case 3, and (d) case 4 .

Take phase $\mathrm{A}$ in the excitation section as an example:

Case 1: Phase A is a positive voltage loop, and phases $\mathrm{B}, \mathrm{C}$, and $\mathrm{D}$ are all negative voltage loops. Therefore, the DC-bus current $i_{\mathrm{O}}=i_{\mathrm{A}}-i_{\mathrm{B}}-i_{\mathrm{C}}-i_{\mathrm{D}}$ as shown in Figure 10a.

Case 2: Phase A is a positive voltage loop, and phases B, C, and D are all zero-voltage loops. Therefore, the DC-bus current $i_{\mathrm{o}}=i_{\mathrm{A}}$ as shown in Figure 10b.

Case 3: Phases A, B, C, and D are all zero-voltage loops. Therefore, the DC-bus current $i_{\mathrm{o}}=0$ as shown in Figure 10c.

Case 4: Phase A is a zero-voltage loop, and phases B, C, and D are all negative voltage loops. Therefore, the DC-bus current $i_{\mathrm{O}}=-i_{\mathrm{B}}-i_{\mathrm{C}}-i_{\mathrm{D}}$ as shown in Figure $10 \mathrm{~d}$.

In the above four cases, the DC-bus current of case 2 and case 4 are positive and negative, respectively. The DC-bus current of case 3 gradually increases from a negative value, for which the final value is related to the conduction angle of SRD and DC voltage. Assume that the carrier frequencies of the upper and lower devices are $f_{\mathrm{u}}$ and $f_{\mathrm{d}}$, respectively. At the same time, the duty cycle of the lower devices is constant at 0.5 , while the duty cycle of the upper devices changes with the actual rotation speed. Referring to the above analysis of the bus current, in the case of $f_{\mathrm{u}} \neq f_{\mathrm{d}}$, the bus current will include the four combinations above. When $f_{\mathrm{u}}=2 f_{\mathrm{d}}$, it can be seen from Figure 11 that the current waveform is not a smooth curve but jumps at the rising and falling edges of higher frequency $\left(f_{\mathfrak{u}}\right)$. In a half cycle of the lower frequency $\left(f_{\mathrm{d}}\right)$, the DC-bus current switches between the two cases, while in the other half cycle, it switches between the other two cases. If SRD is not controlled with a closed loop, the driving signals of the upper device are single pulse, meaning that the devices remain normally closed. Meanwhile, the lower device turns on and off depending on $v_{\mathrm{dd}}$ and cooperates with the upper device to change between cases 1 and 2. Thus, the DC-bus current is relatively flat compared to that in Figure 11, but there are also some jumps. 


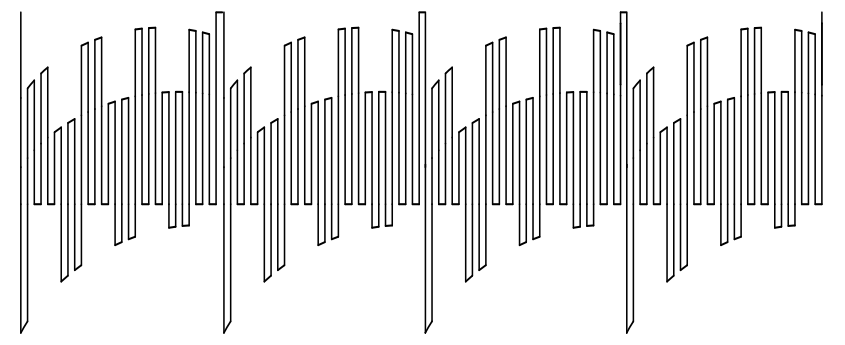

Figure 11. Waveform of DC-bus.

In the case of speed open-loop control, the carrier frequency of upper devices $f_{\mathrm{u}}$ is zero. In order to reduce disturbance and to avoid introducing other frequency components, the carrier frequency $f_{\mathrm{d}}$ of the lower devices should be chosen to meet the integer multiple of the commutation frequency. However, in the case of speed closed-loop control, $f_{\mathrm{u}}$ is not equal to zero. Therefore, disturbance will occur in the frequency spectrum if $f_{\mathrm{u}}$ is similar to $f_{\mathrm{d}}$, thus interfering with the demodulation of the signal. Therefore, $f_{\mathrm{u}}$ should be appropriately larger or smaller than $f_{\mathrm{d}}$ to ensure the detection of frequency $f_{\mathrm{d}}$.

\section{Analysis of the DC-Bus Ripple}

The synchronous transmission of energy and signal proposed in this paper is realized by using the ripple generated on the DC-bus from the switching of the motor power converter. The signal demodulation only calls for the switching ripple of SRD, but the system includes the commutation ripple and the switching ripple of the former boost circuit. The setup of the experimental system is shown in Figure 12.

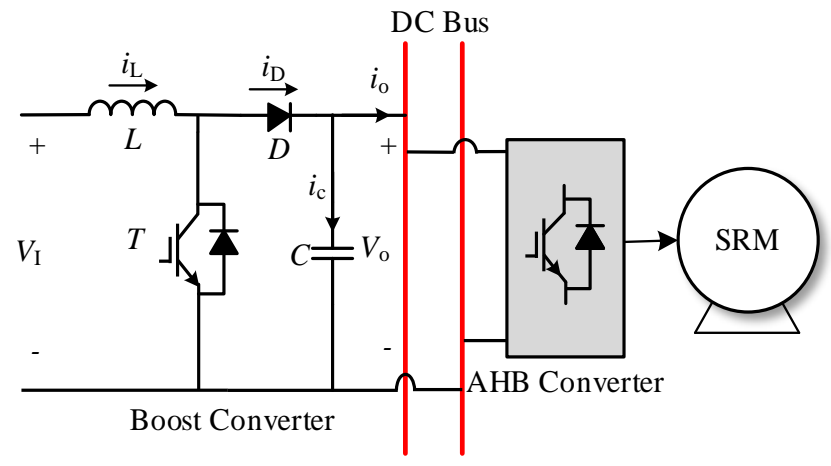

Figure 12. Setup of the experimental system.

In the boost converter, the inductor current will pass through a critical point. Such charging and discharging processes add up to a complete cycle. The waveforms of current are shown in Figure 13, where $I_{\mathrm{LM}}$ and $I_{\mathrm{I}}$ are the maximum value and average value of the inductor current, respectively. $I_{\mathrm{I}}$ is half of the maximum inductor current $I_{\mathrm{LM}}$. $T_{\mathrm{Bon}}$ and $T_{\mathrm{Boff}}$ are the turn-on and turn-off times of the boost circuit, respectively.

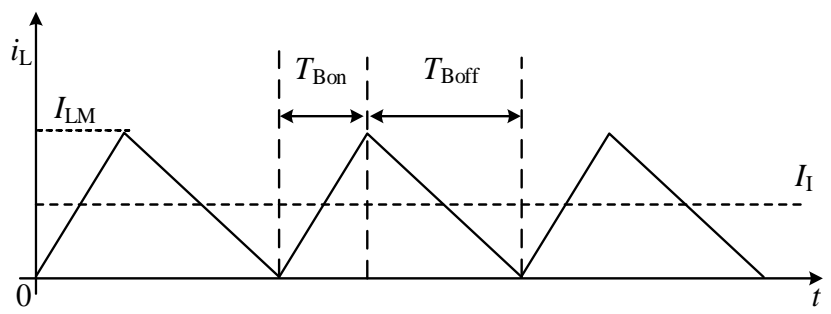

Figure 13. Current waveform of the boost circuit under critical state. 
According to the law of conservation of energy,

$$
V_{\mathrm{I}} I_{\mathrm{I}}=V_{0} I_{0}
$$

Therefore, the critical inductance $L_{C}$ is

$$
L_{\mathrm{C}}=\frac{T_{\mathrm{Boost}} V_{o} d(1-d)^{2}}{2 I_{o}}
$$

where $T_{\text {Boost }}$ is the switching period of the boost circuit, $d$ is the corresponding duty cycle, and $I_{\mathrm{O}}$ is the average value of the output current $i_{\mathrm{o}}$.

When the inductance is greater than $L_{C}$, the boost circuit is in continuous conduction mode (CCM). According to [22], the boost circuit can be classified into complete inductor power supply mode (CISM) $\left(I_{\mathrm{Lm}}>I_{\mathrm{O}}\right)$ and incomplete inductor power supply mode (IISM) $\left(I_{\mathrm{Lm}}<I_{\mathrm{O}}\right)$. The waveforms of inductor current and capacitor voltage are shown in Figure 14 below.

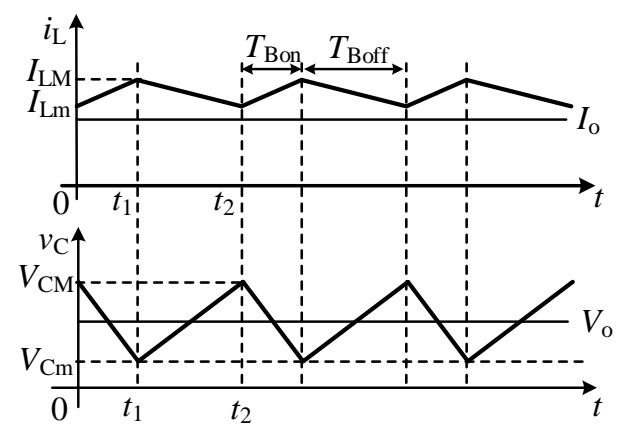

(a)

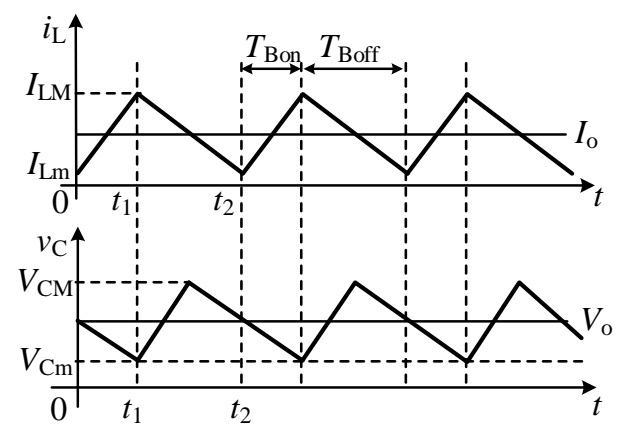

(b)

Figure 14. The inductor current and capacitor voltage waveforms of a continuous conduction mode (CCM) boost circuit: (a) the waveform of the complete inductor power supply mode (CISM) and (b) the waveform of the incomplete inductor power supply mode (IISM).

It can be seen from Figure 12 that $i_{\mathrm{o}}$ is the output current of the boost converter, which is equal to the sum of four phase currents of SRG. The one-phase current of SRD under linear model is

$$
\begin{gathered}
i(\theta)= \begin{cases}\frac{V_{o}}{L_{\text {min }}} \frac{\theta-\theta_{\text {on }}}{\omega} & \theta_{\text {on }} \leq \theta<\theta_{2} \\
\frac{V_{o}}{L \prime} \frac{\theta-\theta_{\text {on }}}{\omega} & \theta_{2} \leq \theta<\theta_{\text {off }} \\
\frac{V_{o}}{L^{\prime}} \frac{2 \theta_{\text {off }}-\theta_{\text {on }}-\theta}{\omega} & \theta_{\text {off }} \leq \theta<\theta_{3} \\
\frac{V_{o}}{L_{\text {max }}} \frac{2 \theta_{\text {off }}-\theta_{\text {on }}-\theta}{\omega} & \theta_{3} \leq \theta<\theta_{4} \\
\frac{V_{o}}{L^{\prime}} \frac{2 \theta_{\text {off }}-\theta_{\text {on }}-\theta}{\omega} & \theta_{4} \leq \theta<\theta_{5}\end{cases} \\
L^{\prime}=L_{\text {min }}+K\left(\theta-\theta_{2}\right) \\
K=\left(L_{\max }-L_{\min }\right)\left(\theta_{3}-\theta_{2}\right)
\end{gathered}
$$

where $L_{\min }$ and $L_{\max }$ are the minimum and maximum inductance where the stator tooth pole coincides with the rotor slot axis, respectively.

For four phase $8 / 6 \mathrm{SRG}$, the conduction angle is $15^{\circ}$, assuming there is no overlap angle for any two phases. During operation, the angle $\theta_{z}$ alters inside $\left(\theta_{3}, \theta_{5}\right)$ when the current drops to zero. The input current of the SRD $i_{\mathrm{o}}$ can be expressed as

$$
i_{\mathrm{o}}=\sum_{\mathrm{k}=1}^{4} i_{\mathrm{k}}(\theta)
$$


when $\theta_{\mathrm{z}}-\theta_{\text {off }} \leq \theta_{2}-\theta_{\text {on }}$

$$
i_{\mathrm{o}}= \begin{cases}\frac{V_{o}}{L_{\min }} \frac{\theta-\theta_{\text {on }}}{\omega}-\frac{V_{o}}{L^{\prime}} \frac{2 \theta_{\text {off }}-\theta_{\text {on }}-(\theta+15)}{\omega} & \theta_{\text {on }} \leq \theta<\theta_{\mathrm{z}}-15^{\circ} \\ V_{\mathrm{o}} & \theta_{\mathrm{z}}-15^{\circ} \leq \theta<\theta_{2} \\ \frac{V_{o}}{L^{\prime}} \frac{\theta-\theta_{\text {on }}}{\omega} & \theta_{2} \leq \theta<\theta_{\text {off }}\end{cases}
$$

When $\theta_{z}-\theta_{\text {off }}>\theta_{2}-\theta_{\text {on, }}$ we have

$$
i_{\mathrm{o}}=\left\{\begin{array}{lc}
\frac{V_{o}}{L_{\min }} \frac{\theta-\theta_{\text {on }}}{\omega}-\frac{V_{o}}{L \prime} \frac{2 \theta_{\text {off }}-\theta_{\text {on }}-(\theta+15)}{\omega} & \theta_{\text {on }} \leq \theta<\theta_{2} \\
\frac{V_{o}}{L^{\prime}} \frac{\theta-\theta_{\text {on }}}{\omega}-\frac{V_{o}}{L^{\prime}} \frac{2 \theta_{\text {off }}-\theta_{\text {on }}-(\theta+15)}{\omega} & \theta_{2} \leq \theta<\theta_{\mathrm{z}}-15^{\circ} \\
\frac{V_{o}}{L^{\prime}} \frac{\theta-\theta_{\text {on }}}{\omega} & \theta_{\mathrm{z}}-15^{\circ} \leq \theta_{\text {off }}
\end{array}\right.
$$

Since a step angle of an $8 / 6 \mathrm{SRD}$ is $15^{\circ}, i_{\mathrm{o}}$ is a periodic variable. Assuming that the motor speed is $r$, the period is $1 /(0.4 r)$. Thus, the average current in the above two cases are as follows:

$$
\begin{gathered}
I_{0}=\frac{12}{\pi}\left[\int_{\theta_{\text {on }}}^{\theta_{\mathrm{o}}-15}\left(\frac{V_{o}}{L_{\text {min }}} \frac{\theta-\theta_{\text {on }}}{\omega}-\frac{V_{o}}{L^{\prime}} \frac{2 \theta_{\text {off }}-\theta_{\text {on }}-\theta-15}{\omega}\right) d \theta\right. \\
\left.+\int_{\theta_{\mathrm{z}}-15}^{\theta_{2}} \frac{V_{o}}{L_{\text {min }}} \frac{\theta-\theta_{\text {on }}}{\omega} d \theta+\int_{\theta_{2}}^{\theta_{\text {off }}} \frac{V_{o}}{L^{\prime}} \frac{\theta-\theta_{\text {on }}}{\omega} d \theta\right] \\
I_{0}=\frac{12}{\pi}\left[\int_{\theta_{\text {on }}}^{\theta_{2}}\left(\frac{V_{o}}{L_{\text {min }}} \frac{\theta-\theta_{\text {on }}}{\omega}-\frac{V_{o}}{L \prime} \frac{2 \theta_{\text {off }}-\theta_{\text {on }}-\theta-15}{\omega}\right) d \theta\right. \\
\left.+\int_{\theta_{2}}^{\theta_{\mathrm{z}}-15^{\circ}}\left(\frac{V_{o}}{L \prime} \frac{\theta-\theta_{\text {on }}}{\omega}-\frac{V_{o}}{L \prime} \frac{2 \theta_{\text {off }}-\theta_{\text {on }}-\theta-15}{\omega}\right) d \theta+\int_{\theta_{\mathrm{z}}-15^{\circ}}^{\theta_{\text {off }}} \frac{V_{o}}{L} \frac{\theta-\theta_{\text {on }}}{\omega} d \theta\right]
\end{gathered}
$$

By substituting $I_{\mathrm{O}}$ into Equation (11), the critical inductance can be obtained. The corresponding voltage ripples in CISM and IISM modes are as follows:

$$
\begin{gathered}
\left|\Delta V_{\mathrm{C} 1}\right|=\left|\frac{d T_{\text {Boost }} I_{o}}{C}\right| \\
\left|\Delta V_{\mathrm{C} 1}\right|=\left|\frac{V_{o}-V_{\mathrm{I}}}{2 C V_{o}}\left(\frac{L V_{o} I_{o}^{2}}{V_{\mathrm{I}}^{2}}+\frac{V_{\mathrm{I}}^{2}}{4 L f_{\text {Boost }}{ }^{2} V_{o}}+\frac{I_{o}}{f_{\text {Boost }}}\right)\right|
\end{gathered}
$$

where $f_{\text {Boost }}=1 / T_{\text {Boost }}$. According to Figure 12, the capacitor current and voltage should meet

$$
\left\{\begin{array}{l}
i_{\mathrm{c}}(t)=i_{\mathrm{D}}(t)-i_{o}(t) \\
u_{\mathrm{c}}(t)=\frac{1}{\mathrm{C}} \int i_{\mathrm{c}}(t) d t
\end{array}\right.
$$

Since the commutation frequency is much lower than the switching frequency of the boost circuit, $i_{\mathrm{D}}$ can be approximated as a stable continuous current $I_{\mathrm{I}}$. Let $t_{0}$ be the time corresponding to the minimum of current $i_{\mathrm{o}}$ in the first cycle. When $i_{\mathrm{o}}=I_{\mathrm{I}}$, the corresponding time is labeled as $t_{\mathrm{I}}$. Thus, the commutation voltage ripples of the motor can be expressed as

$$
\left|\Delta V_{\mathrm{H}}\right|=\left|\frac{1}{C} \int_{t_{0}}^{t_{\mathrm{I}}}\left(I_{\mathrm{I}}-i_{\mathrm{o}}\right) d t\right|
$$

Normally, $i_{\mathrm{o}}$ reaches the peak at $\theta_{2}$, and $t_{\mathrm{I}}$ meets the following condition

$$
t_{\mathrm{I}} \leq \frac{\theta_{2}-\theta_{\mathrm{on}}}{\omega}
$$

Hence, in Equations (16) and (17), when $\theta_{\mathrm{I}}<\theta_{\mathrm{z}}-\theta_{\text {off, we have }}$

$$
\left|\Delta V_{\mathrm{H}}\right|=\left|\frac{1}{C} \int_{\theta_{0}}^{\theta_{\mathrm{I}}}\left(I_{\mathrm{I}}-\frac{V_{o}}{L_{\min }} \frac{\theta-\theta_{\mathrm{on}}}{\omega}+\frac{V_{o}}{L^{\prime}} \frac{2 \theta_{\text {off }}-\theta_{\text {on }}-\theta-15}{\omega}\right) d \theta\right|
$$


In Equation (16), when $\theta_{\mathrm{I}} \geq \theta_{\mathrm{z}}-\theta_{\text {off }}$

$$
\left|\Delta V_{\mathrm{H}}\right|=\left|\frac{1}{C}\left\{\int_{\theta_{0}}^{\theta_{z}-\theta_{\text {off }}}\left[I_{\mathrm{I}}-\frac{V_{o}}{\omega} \frac{\theta-\theta_{\text {on }}}{L_{\text {min }}}+\frac{V_{o}}{\omega} \frac{2 \theta_{\text {off }}-\theta_{\text {on }}-\theta-15}{L^{\prime}}\right] d \theta+\int_{\theta_{z}-\theta_{\text {off }}}^{\theta_{\mathrm{I}}}\left(I_{\mathrm{I}}-\frac{V_{o}}{L_{\text {min }}} \frac{\theta-\theta_{\text {on }}}{\omega}\right) d \theta\right\}\right|
$$

where $\theta_{0}$ and $\theta_{\mathrm{I}}$ are the angles corresponding to $t_{0}$ and $t_{\mathrm{I}}$, respectively. It can be seen from the above equations that the amplitude of the commutation ripple is proportional to the excitation voltage and turn-off angle of SRD and is inversely proportional to the rotational angular speed of the motor.

For the ripples caused by the driving signal of the SRD, there will be multiple driving signal cycles during one oscillation period of $i_{\mathrm{c}}$, since the frequency of the driving signal is greater than the commutation frequency. Once the cycle width of the driving signal is determined, the length of the integration interval is also determined. However, $i_{\mathrm{c}}$ in the corresponding interval is different, so the maximum value of the ripple amplitude should be taken as

$$
\begin{aligned}
& \left|\Delta V_{\mathrm{Q}}\right|=\max \left\{\left|\Delta V_{\mathrm{Q} 1}\right|,\left|\Delta V_{\mathrm{Q} 2}\right|, \ldots,\left|\Delta V_{\mathrm{Qk}}\right|\right\} \\
& \left|\Delta V_{\mathrm{Qk}}\right|=\left|\frac{1}{\mathrm{C}} \int_{t_{\mathrm{k}}}^{t_{\mathrm{I}}}\left(I_{\mathrm{I}}-i_{\mathrm{O}}\right) d t\right|
\end{aligned}
$$

where $t_{\mathrm{k}}$ and $t_{\mathrm{Ik}}$ are the moments corresponding to the rising and falling edges of the drive signal, respectively. The amplitude of the ripple is inversely proportional to the frequency of the drive signal and DC-bus capacitance.

\section{Modulation and Demodulation Methods}

Usually many converters and loads are connected to the DC-bus. Switching noise disturbance exists among these devices, and the amplitude of the switching harmonics is large. Consequently, both the zero-crossing detection method and the envelope detection method will be interfered with and bit errors will occur. This paper adopts the Fourier transform method to analyze the frequency component corresponding to " 1 " or " 0 " to realize data demodulation.

The signals on the DC-bus modulated by the modulation circuit can be expressed as

$$
s(t)=A_{1} \cos \left(2 \pi f_{1}+\varphi_{1}\right)[1-c(t)]+A_{2} \cos \left(2 \pi f_{2}+\varphi_{2}\right) c(t)
$$

where $c(t)$ should satisfy

$$
c(t)=\left\{\begin{array}{l}
1 \text { sending “ } 0 " \\
0 \text { sending " } 1 \text { " }
\end{array}\right.
$$

$f_{1}$ and $f_{2}$ are the carrier frequencies corresponding to the signals " 1 " and " 0 ", respectively. When calculating the amplitude of signal $f_{1}, \mathrm{~A}_{2}$ is regarded as the amplitude of noise. According to Euler's identity, the exponential form of Equation (28) is expressed as

$$
\begin{gathered}
s(t)=\sum_{n=-\infty}^{\infty} F_{n} e^{j 2 \pi n t / T_{\mathrm{s}}} \\
F_{n}=\frac{1}{T_{\mathrm{s}}} \int_{0}^{T_{\mathrm{s}}} s(t) e^{-j 2 \pi n t / T_{\mathrm{s}}} d t
\end{gathered}
$$

where $n$ is an integer. $f_{1}$ and Fourier calculation period $T_{\mathrm{s}}$ should satisfy

$$
f_{1}=\frac{m_{1}}{T_{\mathrm{s}}}=m_{1} f_{\mathrm{s}}
$$

In Equation (32), $m_{1}$ is an integer and $f_{\mathrm{s}}$ is the fundamental frequency. It is apparent that the signal with frequency $f_{1}$ is the $m_{1}$ th-order harmonic component of $s(t)$. Therefore, the amplitude of $m_{1}$ th-order harmonic component can be determined by $F_{n}$. 
In order to eliminate the influence of frequency $f_{2}$ on $f_{1}$,

$$
\int_{0}^{T_{\mathrm{s}}} A_{1} \cos \left(2 \pi f_{2}+\varphi_{2}\right) e^{-j 2 \pi n t / T_{\mathrm{s}}} d t=0
$$

The above Equation shows that $f_{2}$ is also an integer multiple of $f_{\mathrm{s}}$, so it satisfies the orthogonal relationship with $f_{1}$ in the Fourier calculation period.

2FSK digital demodulation algorithm is to calculate the amplitude of the corresponding carrier through Fourier transform. According to Nyquist theorem, the sampling frequency $f_{\text {smp }}$ should satisfy

$$
f_{\mathrm{smp}} \geq 2 \max \left\{f_{1}, f_{2}\right\}
$$

Assuming that $N$ points are sampled at each cycle $T_{\mathrm{s}}$ with a frequency $f_{\mathrm{smp}}$, then

$$
f_{\text {smp }}=N f_{\mathrm{s}}
$$

The sampling sequence is $\{s(n), n=0,1,2 \ldots, N-1\}$, then the discrete Fourier transform (DFT) of $s(n)$ is

$$
S(k)=\sum_{n=0}^{N-1} s(n) e^{-j \frac{2 \pi k}{N} n}(n=0,1,2, \ldots, N-1)
$$

According to Equation (32), $f_{1}$ is an integer multiple of the fundamental frequency $f_{\mathrm{s}}$, and then, the frequency component of $f_{1}$ is the $m_{1}$ th-order harmonic of the DFT transform in Equation (36). Thus, its amplitude is

$$
S\left(m_{1}\right)=\sum_{n=0}^{N-1} s(n) e^{-j \frac{2 \pi m_{1}}{N} n}
$$

Because the sending and the receiving terminal of the system cannot achieve synchronization, in order to reduce the delay caused by performing a DFT transformation every cycle, a DFT transformation is performed when a value is sampled. Since this will increase the calculation of the algorithm, the iterative algorithm of DFT can be used.

Supposing that the current sequence is $\{s(0), s(1), \ldots, s(N-1)\}$ and that the next sequence is $\{s(1)$, $s(2), \ldots, s(N)\}$, the amplitude of the $m_{1}$ th-order harmonic calculated in this sequence is

$$
S_{1}\left(m_{1}\right)=\sum_{n=0}^{N-1} s(n+1) e^{-j \frac{2 \pi m_{1}}{N} n}
$$

because

$$
e^{-j \frac{2 \pi m_{1}}{N} N}=1
$$

Equation (38) can be written as

$$
S_{1}\left(m_{1}\right)=\left[S\left(m_{1}\right)+s(N)-s(0)\right] e^{j \frac{2 \pi m_{1}}{N}}
$$

Compared to the original discrete Fourier calculation, it can be seen from the above iteration formula that each operation only needs to execute two addition and subtraction instructions and one multiplication instruction, which greatly reduces the amount of calculation. Because the $N$ sampling points are taken at each cycle $T_{\mathrm{s}}$ with the frequency $f_{\mathrm{smp}}$, when the sampling is refreshed, it can be considered that the window of length $T_{\mathrm{s}}$ moves by one sampling interval, and an amplitude value of frequency $f_{1}$ is obtained. The demodulation process is shown in Figure 15 below. 


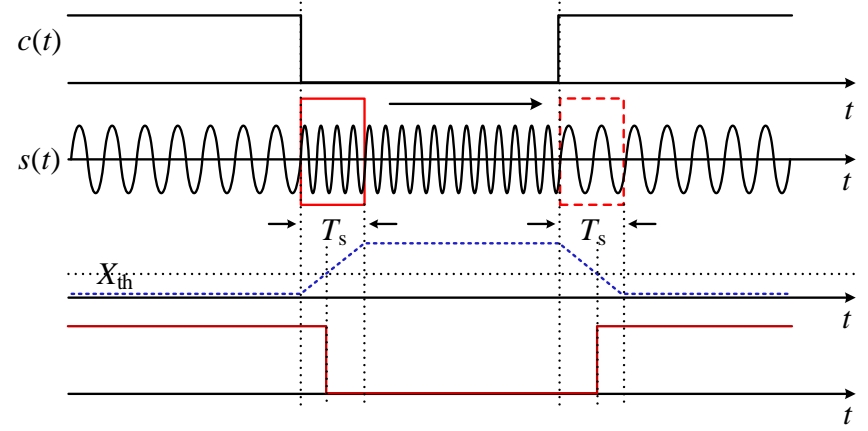

Figure 15. The demodulation process.

Strictly speaking, the addition of signal modulation strategy will certainly impact the operation performance of SRD system since extra voltage ripples are injected onto the power bus. For Amplitude Shift Keying (ASK), the voltage ripple amplitude must be maintained at a relatively high level in order to guarantee the demodulation accuracy. With regards to FSK, the data is carried by high frequency voltage ripples and demodulated by the Fast Fourier Transform (FFT) method. Hence, the voltage ripple for carrying data can be configured with a smaller amplitude since ripple frequency is used for demodulation. In addition, 2FSK is adopted for power and signal synchronous transmission but only in the freewheeling operation stage. Note that conventional control strategies for SRD, such as Angular Position Control (APC), Current Chopper Control (CCC), and Voltage Control (VC), are only activated in the excitation stage of SRD. Hence, the signal modulation applied only in the freewheeling stage will not degrade the control performance of SRD. It can be found that, under the proposed modulation strategy, the Root Mean Square (RMS) value of phase current is larger, which is beneficial for producing higher electromagnetic torque.

\section{Simulation and Experiments}

In order to verify the feasibility of the proposed method, MATLAB/Simulink was adopted to build the simulation system.

The transmitted signal is a square wave with a frequency of $50 \mathrm{~Hz}$. The two carrier frequencies used by $2 \mathrm{FSK}$ are set to $10 \mathrm{kHz}$ and $8 \mathrm{kHz}$, and the output voltage of the boost converter is $57 \mathrm{~V}$.

It can be seen from Figure 16 that, when the rotation speed is $1000 \mathrm{r} / \mathrm{min}$, the commutation frequency is $400 \mathrm{~Hz}$. The current of DC-bus is not a smooth curve, and there is a jump periodically.

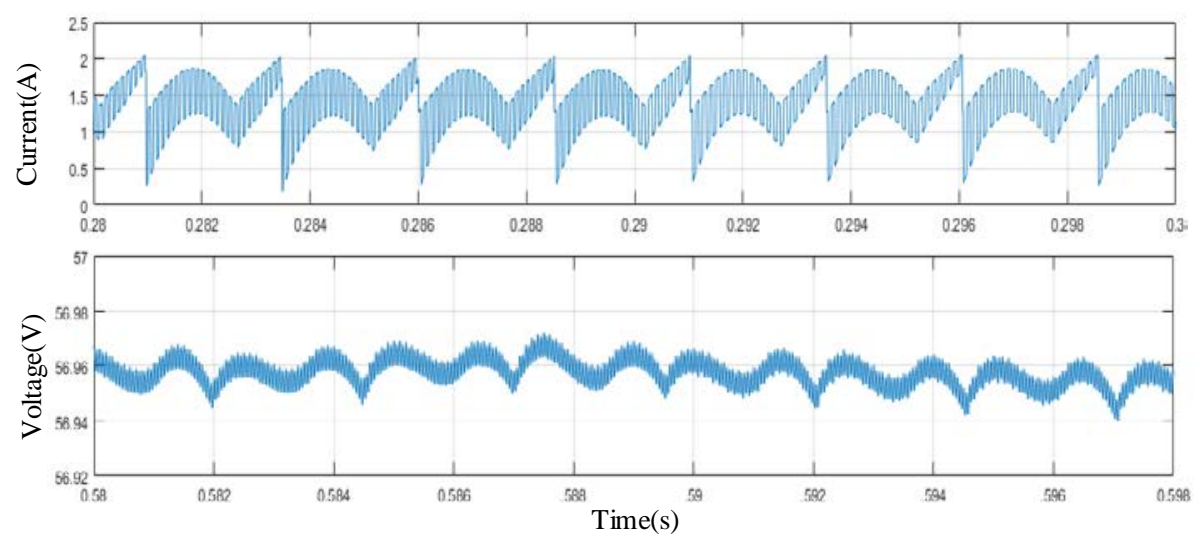

Figure 16. Current and voltage of DC-bus.

Signal modulation is performed on the upper and the lower devices. The waveform of a DC-bus current is shown in Figure 17. The figure shows the current waveforms corresponding to the signal modulation of the upper and the lower devices at the same time. The two sets of simulated waveforms 
are almost identical, which is in accordance with the structural characteristics of the asymmetrical half-bridge power converter of the SRD.
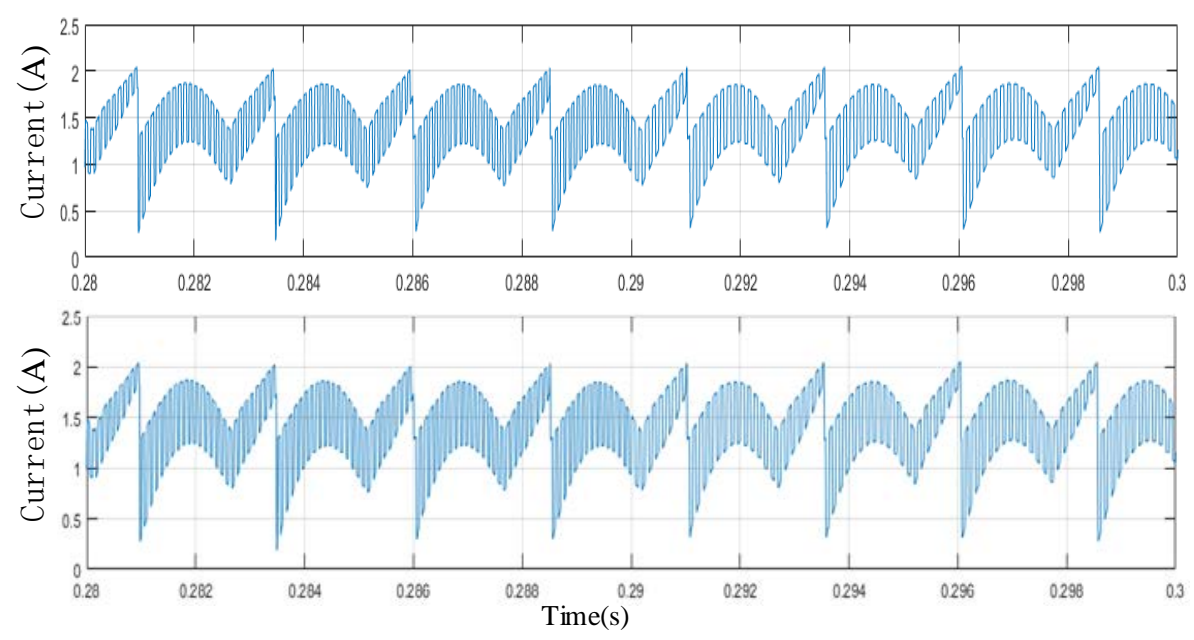

Figure 17. DC-bus current after signal modulation on upper and lower devices.

The current shown in Figure 18 is the waveform when the conduction angle is $15^{\circ}$. Unlike the bus current with a conduction angle of $20^{\circ}$ in Figure 17, the current rises and falls only once per cycle and does not rise again after the fall. The reason for this difference is that, at $20^{\circ}$ conduction angle, there is an overlap angle of $5^{\circ}$ between the former and the latter phases of the motor. The direction of the current is consistent with the negative direction of the DC-bus current after the turn-off angle. The DC-bus current superimposes at this position to produce a sudden change.

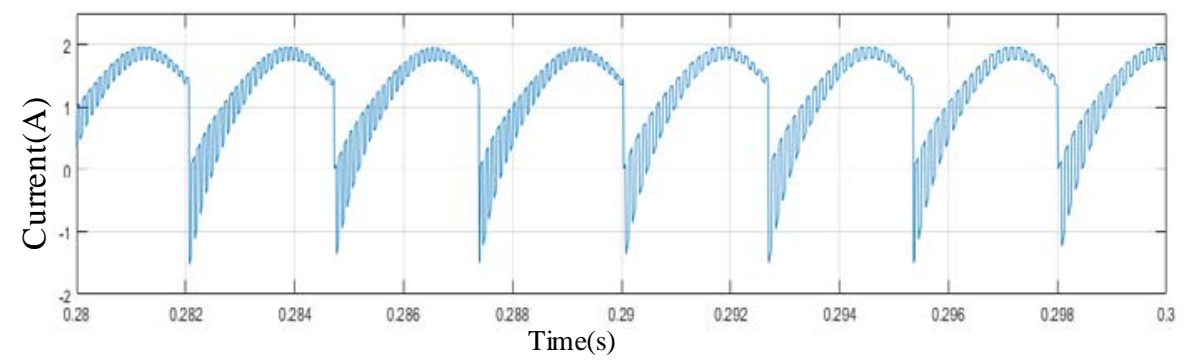

Figure 18. DC-bus current with $15^{\circ}$ conduction angle.

Figure 19 shows the DC-bus currents corresponding to the conduction angles of $15^{\circ}$ and $20^{\circ}$ under the speed closed-loop control. To verify the above analysis, the carrier frequency of upper devices is set to twice that of the lower devices. In this case, the DC-bus current switches in four cases and the minimum value is negative, which is consistent with the above analysis. The curve obtained after the analysis of frequency spectrum is shown in Figure 20 below. Figure 21 is a transmission signal waveform obtained after threshold value judgment. 


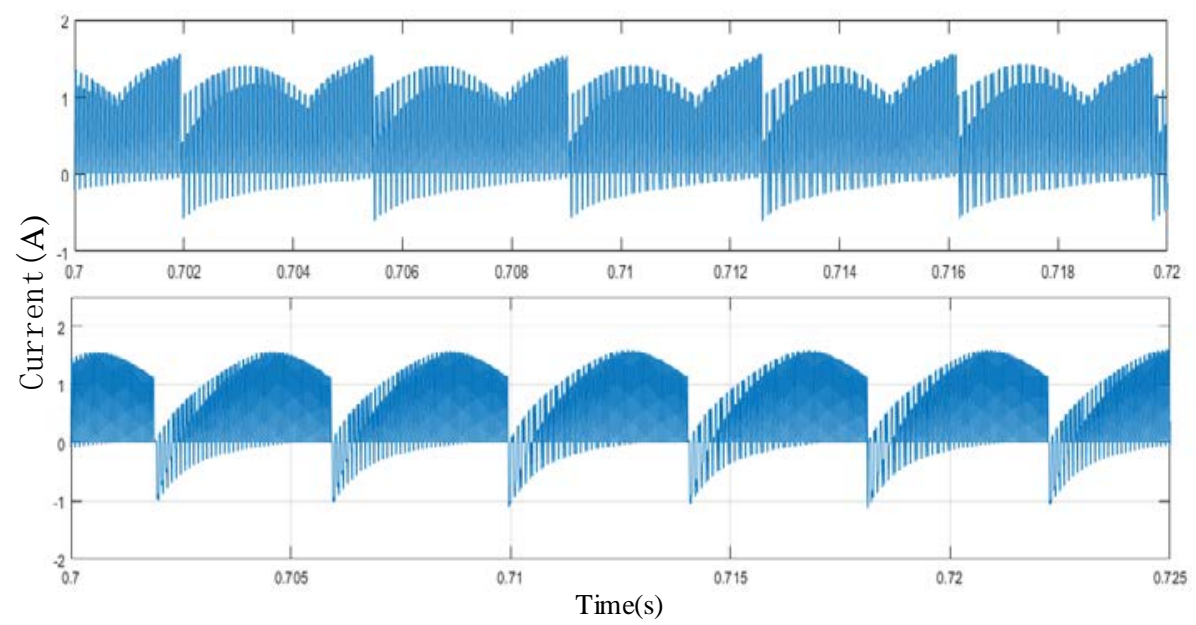

Figure 19. DC-bus current with speed closed-loop.

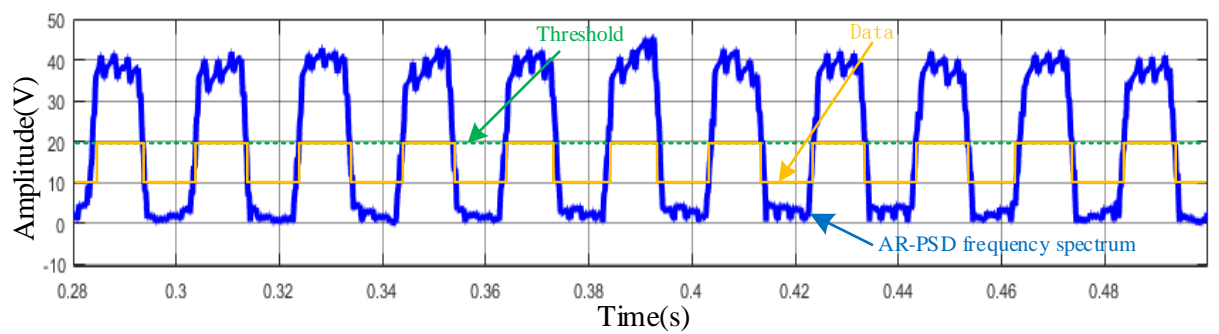

Figure 20. Frequency spectrum for DC-bus current signals.

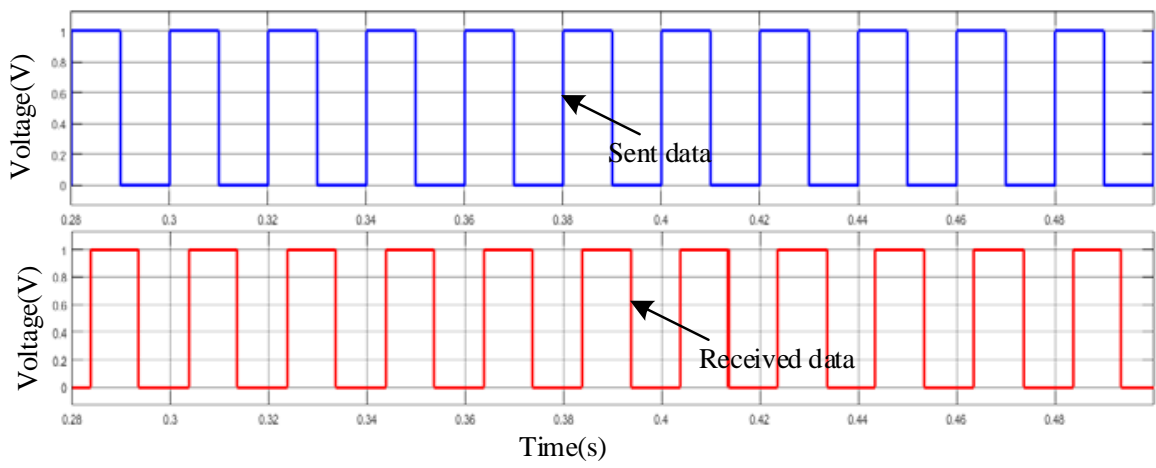

Figure 21. Simulation results of signal sending and receiving.

It can be seen from Figure 21 that transmitted signal can be successfully recovered at the receiving terminal after being modulated by the proposed method and that there is a certain delay compared with the original signal. Moreover, if the SRD adopts open-loop speed control, the carrier frequency of the upper devices is 0 , which also meets a certain difference with that of the lower ones, and achieves demodulation of the signal.

In order to reveal the goodness of the proposed power and signal composite modulation strategy, the data is transmitted under three operation cases: (1) the speed is changed from $1000 \mathrm{r} / \mathrm{min}$ to $800 \mathrm{r} / \mathrm{min}$; (2) the load is reduced from $20 \mathrm{Nm}$ to $15 \mathrm{Nm}$; and (3) the transmission line is lengthened to $500 \mathrm{~m}$ with $4 \mathrm{Ohm}$ resistance. The received signal is demodulated, and the frequency spectrum as well as the data is presented in Figures 22-24, respectively, as shown below. 


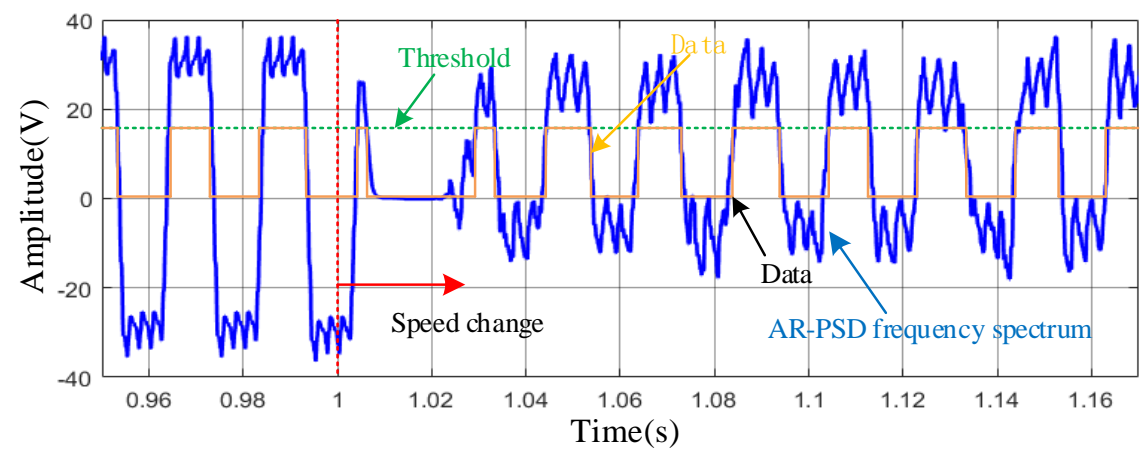

Figure 22. Frequency spectrum and demodulated data as the speed is changed from $1000 \mathrm{r} / \mathrm{min}$ to $800 \mathrm{r} / \mathrm{min}$.

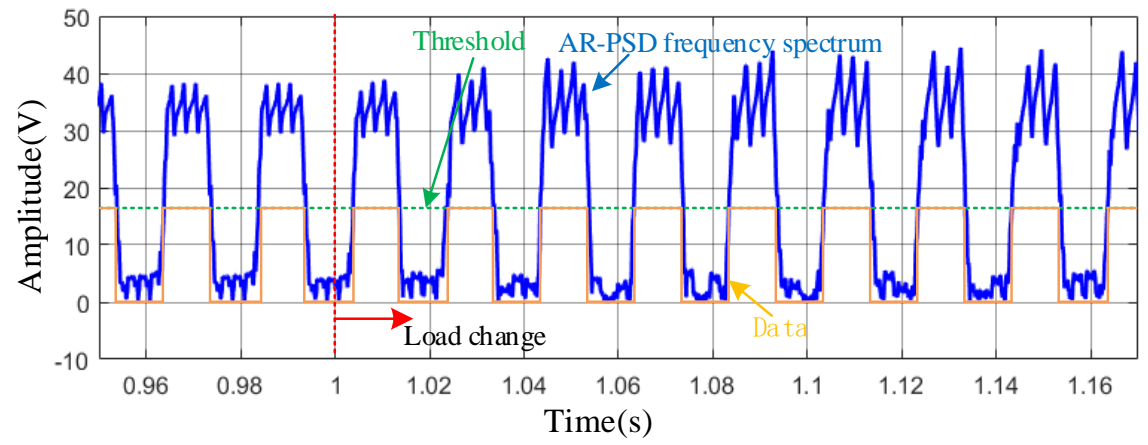

Figure 23. Frequency spectrum and demodulated data as the load is reduced from $20 \mathrm{Nm}$ to $15 \mathrm{Nm}$.

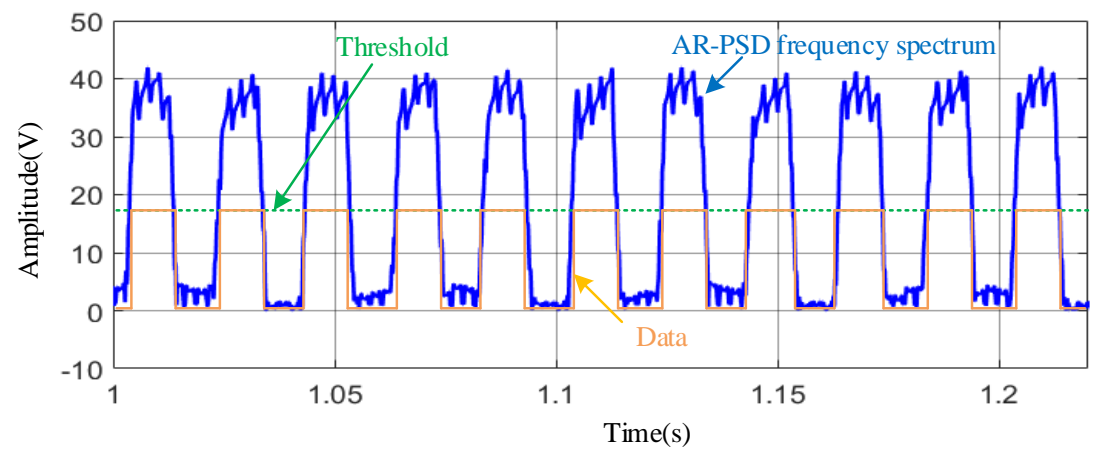

Figure 24. Frequency spectrum and demodulated data as the transmission resistance is $4 \mathrm{Ohm}$.

It can be seen that the demodulated data can be greatly influenced by the speed change. During the speed change transient, the width of each demodulated data is narrowed, which might degrade the data transmission performance. However, the data can be accurately demodulated as the speed is stabilized to the targeted reference, as shown in Figure 22. As the load is reduced from $20 \mathrm{Nm}$ to $15 \mathrm{Nm}$, the data can be demodulated without deterioration, as shown in Figure 23. The transmission line is lengthened to $350 \mathrm{~m}$ with $4 \mathrm{Ohm}$ resistance, and the frequency spectrum and demodulated data of the received signal are presented in Figure 24. This result show that the frequency spectrum can still maintain high amplitude for data demodulation, which is good for anti-interference. These above results interpret the good performance of the proposed strategy.

If the carrier frequencies of the upper and lower devices are both set as $10 \mathrm{kHz}$, the result of the DC-bus current after spectrum analysis is shown in Figure 25. It can be seen from the analysis that the spectrum is much worse than that in Figure 20. Therefore, such a setting will cause bit errors in demodulation. In order to reduce the bit error rate, the carrier frequency of the upper devices needs to avoid being close to the lower ones. 


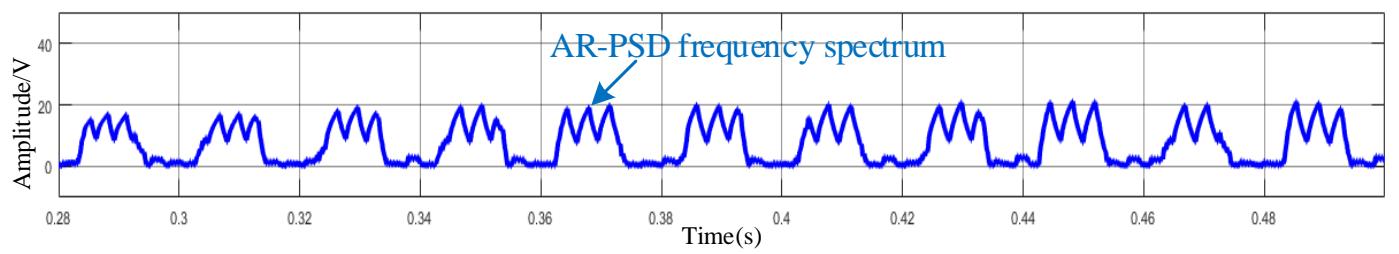

Figure 25. Frequency spectrum with similar frequency.

Experimental platform is built according to the simulation model, as shown in Figure 26.

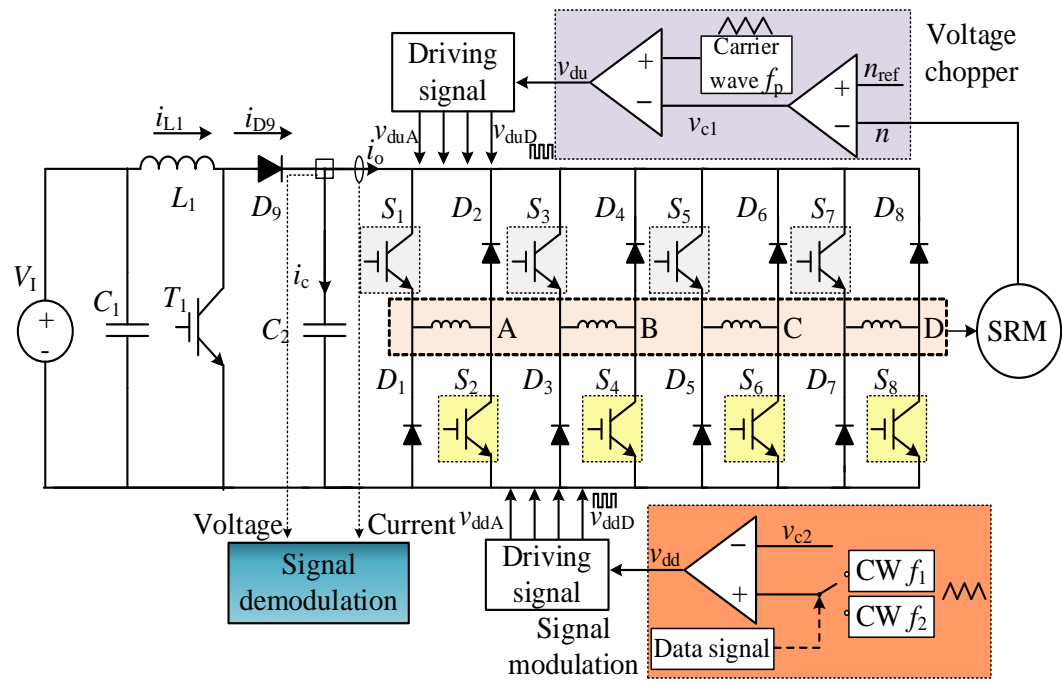

Figure 26. Diagram of the SRD system.

The schematic of the experimental system is shown in Figure 27. When the signal is not transmitted or signal " 0 " is transmitted, the upper and the lower devices of the excitation section maintain normal operation. When signal " 1 " is transmitted, the upper and lower devices are simultaneously applied by a signal of frequency $f_{1}=1.6 \mathrm{kHz}$. The sampling frequency is $16 \mathrm{kHz}$, and the calculation period $T_{\mathrm{S}}$ of Discrete Fourier Transform (DFT) algorithm are set to $3.125 \mathrm{~ms}$. The experimental waveform is shown in Figure 28, where $u_{1}$ is the DC-bus voltage ripple signal, including the commutation ripples superimposed with the switching harmonic; $u_{2}$ is the DC-bus current signal; and $u_{3}$ is the waveform of harmonic amplitude.

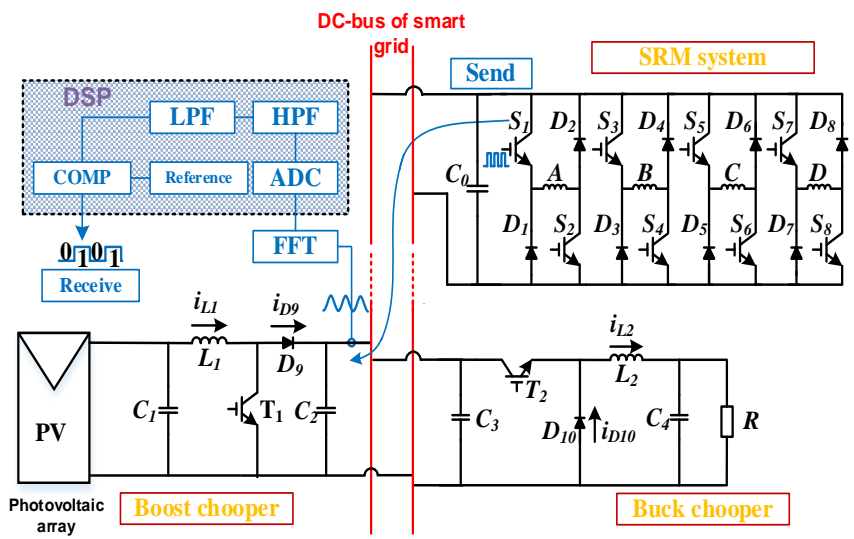

Figure 27. Schematic of the experimental plant. 


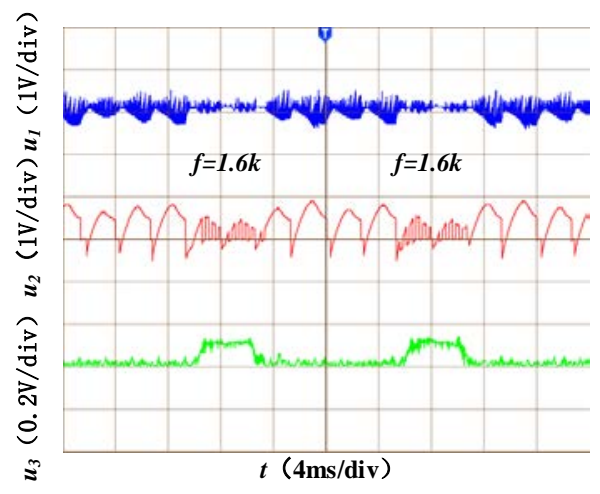

Figure 28. Voltage waveforms.

The signals at the transmitter and receiver are shown in Figure 29, where $u_{1}$ and $u_{2}$ are the transmitted and received signals, respectively. It can be seen that each signal error between $u_{1}$ and $u_{2}$ does not exceed one DFT cycle.

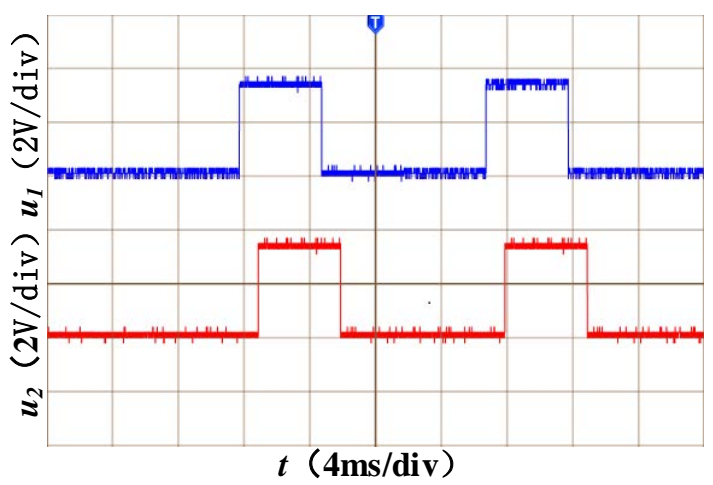

Figure 29. The transmitted data and demodulated data.

\section{Conclusions}

In this paper, a power and signal synchronous transmission strategy is newly proposed for the SRD-integrated DC transmission system. The lower and upper switches of each bridge arm of the SRD converter must be properly controlled to carry out the proposed strategy. During the excitation stage, the two switches are regulated together to stabilize the output speed; during the freewheeling stage, the upper switch is turned off and the lower switch is regulated by the 2FSK modulation signal in order to inject required voltage ripples with specific frequency for carrying data. In the data receiver end, the data can be demodulated by using the FFT method. The most attractive advantage of the proposed method is that no additional hardware circuit is required and, hence, the compatibility is good with low cost and volume. The proposed method could provide a valuable reference for further research of power and signal synchronous transmission between DC power supply interconnected systems with SRM loads.

Author Contributions: Conceptualization, D.Y., C.W. and H.H.C.I.; methodology, F.L.; software, C.W. and X.W.; validation, D.Y. and F.L.; formal analysis, K.L.; writing — original draft preparation, F.L. and C.W.; writing-review and editing, D.Y. All authors have read and agreed to the published version of the manuscript.

Funding: This research was funded by the natural science research project of colleges and universities in Jiangsu Province under grant 19KJB470020.

Conflicts of Interest: The authors declare no conflict of interest. 


\section{References}

1. Pragya Nema, R.K. Nema, Saroj Rangnekar, A Current and Future State of Art Development of Hybrid Energy System Using Wind and PV-solar: A review. Renew. Sustain. Energy Rev. 2009, 13, 2096-2103. [CrossRef]

2. Li, L.; Yonglei, H. The Energy Rebound Effect in Chinese Three Industries Based on Technological Progress. In Proceedings of the 2011 Fourth International Conference on Intelligent Computation Technology and Automation, Shenzhen, China, 28-29 March 2011; pp. 893-896. [CrossRef]

3. Wang, W.; Pan, Z.; Cong, W.; Yu, C.; Gu, F. Impact of Distributed Generation on relay protection and its improved Measures. In Proceedings of the 2008 China International Conference on Electricity Distribution, Guangzhou, China, 10-13 December 2008; pp. 1-5. [CrossRef]

4. Huang, T.; Guo, Q.; Sun, H. A Distributed Computing Platform Supporting Power System Security Knowledge Discovery Based on Online Simulation. IEEE Trans. Smart Grid 2017, 8, 1513-1524. [CrossRef]

5. Chen, Y.; Wang, C.S. Distributed Transient Stability Simulation of Power Systems Based on a Jacobian-Free Newton-GMRES Method. IEEE Trans. Power Syst. 2009, 24, 146-156. [CrossRef]

6. Kalyanaraman, S. Back to the Future: Lessons for Internet of Energy Networks. IEEE Int. Comput. 2016, 20, 60-65. [CrossRef]

7. Liu, J.; Zhao, B.; Wang, J.; Zhu, Y.; Hu, J. Application of Power Line Communication in Smart Power Consumption. In Proceedings of the ISPLC2010, Rio de Janeiro, Brazil, 28-31 March 2010; pp. 303-307. [CrossRef]

8. Unaka, N.J. U.S. Department of Energy. Eur. Asia Stud. 2010, 63, 158-165.

9. Du, J.; Wu, J.; Wang, R.; Lin, Z.; He, X. DC Power-Line Communication Based on Power/Signal Dual Modulation in Phase Shift Full-Bridge Converters. IEEE Trans. Power Electron. 2017, 32, 693-702. [CrossRef]

10. Anatory, J.; Theethayi, N.; Thottappillil, R. Power-Line Communication Channel Model for Interconnected Networks—Part II: Multiconductor System. IEEE Trans. Power Deliv. 2009, 24, 124-128. [CrossRef]

11. Chandna, V.K.; Zahida, M. Effect of Varying Topologies on the Performance of Broadband over Power Line. IEEE Trans. Power Deliv. 2010, 25, 2371-2375. [CrossRef]

12. Li, Y.; Zhang, M.; Zhu, W.; Cheng, M.; Zhou, C.; Wu, Y. Performance evaluation for medium voltage MIMO-OFDM power line communication system. China Commun. 2020, 17, 151-162. [CrossRef]

13. Cataliotti, A.; Cosentino, V.; di Cara, D.; Tine, G. Simulation and Laboratory Experimental Tests of a Line to Shield Medium-Voltage Power-Line Communication System. IEEE Trans. Power Deliv. 2011, 26, 2829-2836. [CrossRef]

14. Bertoni, N.; Bocchi, S.; Mangia, M.; Pareschi, F.; Rovatti, R.; Setti, G. Ripple-based power-line communication in switching DC-DC converters exploiting switching frequency modulation. In Proceedings of the 2015 IEEE International Symposium on Circuits and Systems (ISCAS), Lisbon, Portugal, 24-27 May 2015; pp. $209-212$. [CrossRef]

15. Stefanutti, W.; Mattavelli, P.; Saggini, S.; Panseri, L. Communication on Power Lines Using Frequency and Duty-cycle Modulation in Digitally Controlled DC-DC Converters. IEEE Trans. Ind. Electron. 2008, 55, 1509-1518. [CrossRef]

16. Choi, H.; Jung, J. Enhanced Power Line Communication Strategy for DC Microgrids Using Switching Frequency Modulation of Power Converters. IEEE Trans. Power Electron. 2017, 32, 4140-4144. [CrossRef]

17. Saggini, S.; Stefanutti, W.; Mattavelli, P.; Garcea, G.; Ghioni, M. Power Line Communication in DC-DC Converters Using Switching Frequency Modulation. In Proceedings of the Twenty-First Annual IEEE Applied Power Electronics Conference and Exposition, 2006. APEC ‘06, Dallas, TX, USA, 19-23 March 2006; p. 6. [CrossRef]

18. Stefanutti, W.; Saggini, S.; Mattavelli, P.; Ghioni, M. Power Line Communication in Digitally Controlled DC-DC Converters Using Switching Frequency Modulation. In Proceedings of the 32nd Annual Conference on IEEE Industrial Electronics, Paris, France, 6-10 November 2006; pp. 2144-2149. [CrossRef]

19. Wu, J.; Du, J.; Lin, Z.; Hu, Y.; Zhao, C.; He, X. Power Conversion and Signal Transmission Integration Method Based on Dual Modulation of DC-DC Converters. IEEE Trans. Ind. Electron. 2015, 62, 1291-1300. [CrossRef]

20. Zhu, Z.Q.; Howe, D. Electrical Machines and Drives for Electric, Hybrid, and Fuel Cell Vehicles. Proc. IEEE 2007, 95, 746-765. [CrossRef] 
21. Yu, D.; Hua, Y.; Yu, S.S.; Zhang, P.; Iu, H.H.C. Tyrone Fernando, A New Modulation-Demodulation Approach to DC Power-line Data Transmission for SRG-Integrated Microgrid. IEEE Trans. Power Electron. 2020. [CrossRef]

22. Yu, D.; Wang, X.; Yu, S.; Ye, Z.; Fernando, T.; Iu, H. A Soft-PWM Approach to Power/Signal Synchronous Transmission for SRG based DC Microgrids. IEEE Trans. Ind. Electron. 2019. [CrossRef]

23. SLiu, L.; Liu, J.; Zhong, J. Energy Transmission Modes and Output Ripple Voltage of Buck-Boost Converters. ACTA Electron. SINCA 2007, 35, 838-843.

(C) 2020 by the authors. Licensee MDPI, Basel, Switzerland. This article is an open access article distributed under the terms and conditions of the Creative Commons Attribution (CC BY) license (http://creativecommons.org/licenses/by/4.0/). 